\title{
Levantamentos geológicos e geotécnicos na várzea do rio Paraíba do Sul, Tremembé, SP
}

\author{
Hélio Nóbile Diniz ${ }^{1}$ \\ Jair Santoro ${ }^{1}$ \\ Gabriel da Silva Casaroli ${ }^{1}$ \\ Stéphanie Birrer ${ }^{1}$ \\ ${ }^{1}$ Instituto Geológico do Estado de São Paulo
Av. Miguel Stefano, 3900 - 04301-903 - Água Funda - São Paulo - SP, Brasil \\ \{heliodiniz, jsantoro\}@igeologico.sp.gov.br \\ gabriel_casaroli@msn.com \\ stebirrer@gmail.com
}

\begin{abstract}
This paper presents preliminary results of a survey achieve in the floodplain of Paraíba do Sul river, in Tremembé municipality, refer to the geological / geotechnical characterization of soils and alluvial sediments from the sampling collect during the execution of Standard Penetration Test. The sampling which were sent to the laboratory of the Geological Institute to define lithological and elaborate triangular diagrams of the textural distribution and physical characteristics of soil samples collected at different depths through use correlation formulas were we calculated porosity, saturation degree, void ratio and aeration degree. These parameters will be used for comparison with historical water levels of the water table obtained from field data and the surplus water obtnaided of hydric balance to estimate the rainwater percentage of runoff and infiltration.
\end{abstract}

Palavras-chave índices físicos, análises granulométricas, sondagem à percussão.

\section{Introdução}

O grande crescimento urbano verificado nas cidades do Estado de São Paulo nos últimos 40 anos, principalmente na Região Metropolitana de São Paulo, provocou um aumento na demanda de minerais para construção civil, principalmente os agregados, tais como brita e areia. À medida que a expansão urbana aumentava, os depósitos de areia anteriormente explorados, formado por portos de areia situados nas margens dos rios principais, tais como o rio Tietê e rio Paraíba do Sul, foram sendo esgotados ou impedidos de operarem por não atenderem as normas sanitárias e ambientais vigentes, já que a poluição dos rios também aumentou em função da expansão urbana. Sendo assim, a extração de areia foi deslocada para áreas onde os depósitos apresentavam maiores reservas, tal como ocorre nas planícies de inundação dos rios Tietê e Paraíba do Sul. As cavas situadas na Região Metropolitana de São Paulo e as do Vale do Paraíba do Sul, tornaram-se as melhores opções para a extração e aproveitamento do produto, pois a areia possui baixa relação preço/volume, sendo que $2 / 3$ do seu preço é devido ao transporte entre a área fonte e o local de uso.

Com o esgotamento contínuo dos depósitos situados próximos das áreas urbanas da capital, como é o caso do município de Guarulhos, o Vale do Paraíba do Sul tornou-se a opção mais viável e transformou-se na maior região produtora de areia do país. Em 2000, a produção de areia nesta região era estimada em $750.000 \mathrm{~m}^{3}$ mensais (ANEPAC, 2000), sendo que $80 \%$ dessa produção se destinam, principalmente, a atender à demanda da Região Metropolitana de São Paulo.

A extração de areia no Vale do Paraíba do Sul é praticada através de cavas submersas. Visivelmente, do ponto de vista hidrogeológico, esta prática utilizada no município de Tremembé, é predatória pois, primeiramente os mineradores retiram a capa de solo argiloarenoso (com espessura de até $2 \mathrm{~m}$, pouco permeável, e onde a infiltração é desprezível) 
apropriada para as culturas de arroz e a lançam nas cavas abandonadas situadas nas proximidades. Após, com uma retro-escavadeira, retiram a areia até atingirem o lençol freático, onde instalam uma draga que passa a lançar a areia, junto com a água da cava, em um classificador. A dragagem nunca atinge a profundidade final dos depósitos arenosos, e sempre ficam de 1 a $2 \mathrm{~m}$ de areia não explorada no fundo.

Este tipo de extração, além de destruir a vegetação natural ou os empreendimentos agrícolas, produz grandes lagos abastecidos pelo nível d'água do aqüífero freático. Tal fato tem transformado a área de várzea do rio Paraíba do Sul em vários lagos artificiais. A formação destes lagos acarreta uma perda maior de água para a atmosfera por evaporação, devido à grande superfície de interface ar-água. $\mathrm{O}$ aumento da evaporação na área da bacia hidrográfica do rio Paraíba do Sul pode comprometer as taxas de excedente hídrico, pois a evaporação destas águas superficiais em contato com as águas subterrâneas do aquífero freático pode representar o retorno do total precipitado na área da várzea para a atmosfera (REIS, 2005).

\section{Objetivos}

O presente trabalho apresenta os resultados preliminares do projeto "Interferência entre cavas de extração de areia e o aquífero freático na margem do rio Paraíba do Sul, Município de Tremembé" sob o aspecto geológico e geotécnico.

\section{Aspectos teóricos para obtenção de parâmetros geológico/geotécnicos}

\section{1. Índices Físicos}

Segundo BUENO e VILAR (1984), os Índices Físicos são relações entre as fases ar, água e sólidos, em termos de massas e volume, que servem para caracterizar as condições físicas naturais em que um solo se encontra.

A finalidade de conhecimento dos Índices Físicos é caracterizar o solo, com parâmetros representativos do estado que o mesmo se encontra na época da amostragem (STANCATI et al., 1981).

Para determinar os Indíces Físicos foram coletadas amostras de solos e levadas para laboratório para serem ensaiadas. Em laboratório foram determinados diretamente apenas três índices, quais sejam: umidade natural (\%) segundo a NBR-6457, massa específica dos grãos $\left(\mathrm{g} / \mathrm{cm}^{3}\right)$ segundo a NBR-6508 e massa específica natural $\left(\mathrm{g} / \mathrm{cm}^{3}\right)$, úmida e seca. Os demais parâmetros foram calculados através de fórmulas de correlação entre eles, sendo determinados o Índice de Vazios $(e)$, a Porosidade $(n)$, o Grau de Saturação $\left(S_{\mathrm{r}}\right)$ e o Grau de Aeração $\left(A_{\mathrm{r}}\right)$. A massa específica dos sólidos e as análises granulométricas foram feitas em ensaios à parte, e completam o conhecimento dos Índices Físicos do solo (SANTORO, 1991).

Com os resultados dos ensaios de laboratório, os demais parâmetros foram calculados utilizando-se as fórmulas de correlação (NOGUEIRA, 1995), a saber:

- $\quad$ Índice de Vazios:

$$
e=\frac{\gamma_{s}(1+w)-\gamma}{\gamma}
$$

onde:

$\gamma_{\mathrm{s}}$ - massa específica dos sólidos;

$w$ - teor de umidade;

$\gamma$ - massa específica natural (seca)

- Porosidade: 
onde:

$$
n=\frac{e}{1+e}
$$

$e$ - índice de vazios

- $\quad$ Grau de Saturação:

$$
S r=\frac{\gamma_{s} \cdot w}{e \cdot \gamma_{w}}
$$

onde:

$\gamma_{\mathrm{w}}-$ massa específica da água $\left(1 \mathrm{~g} / \mathrm{cm}^{3}\right)$.

- $\quad$ Grau de aeração

onde:

$$
A=1-S r
$$

$S r$ - grau de saturação

\subsection{Análises Granulométricas}

Os ensaios granulométricos têm por finalidade a obtenção das curvas de distribuição granulométrica do material amostrado (curva de porcentagens acumuladas). Esta por sua vez, segundo BUENO \& VILAR (1984), encontra aplicação prática na caracterização textural do material, na estimativa do coeficiente de permeabilidade e no dimensionamento de filtros de proteção de poços tubulares profundos.

\subsection{Sondagem à percussão}

O Standard Penetration Test (SPT) é um ensaio dinâmico que consiste em cravar no fundo de um furo de sondagem, devidamente limpo, um amostrador padrão. A cravação é feita recorrendo-se a um pilão com 63,5 kgf de peso que cai livremente de uma altura de 75 $\mathrm{cm}$, sobre um batente, que por sua vez está ligado a um conjunto de varas, cuja ponta é o amostrador padrão (ARANHA, et al).

O ensaio de SPT possui inúmeras aplicações como previsão da tensão admissível de fundações diretas e previsão da capacidade de carga de fundações profundas (para construção de futuros empreendimentos), amostragem para identificação de diferentes horizontes e correlações com outras propriedades geotécnicas, sendo estas duas últimas as aplicações do presente trabalho.

\section{Material e Métodos}

\subsection{Localização}

O município de Tremembé, com área de 192,42 $\mathrm{km}^{2}$, situa-se na região do Vale do Paraíba, no leste do Estado de São Paulo. Limita-se a norte-nordeste com o município de Pindamonhangaba, a oeste com Monteiro Lobato e a sul com Taubaté. A área foco do estudo do projeto encontra-se na Figura 1.

\subsection{Determinação dos parâmetros geológicos/geotécnicos}

Os corpos de prova para determinação dos Índices Físicos das amostras naturais foram coletados no solo, em profundidades variáveis entre $0,5 \mathrm{~m}$ e $2,0 \mathrm{~m}$ na área da várzea do rio Paraíba do Sul, em Tremembé, no local de coordenadas 443,708 E e 7463,413 N e altitude de 534,5 m. As análises foram efetuadas no Laboratório de Solos do Departamento de Ciências Agrárias da Universidade de Taubaté. Os resultados obtidos estão na Tabela 1. 


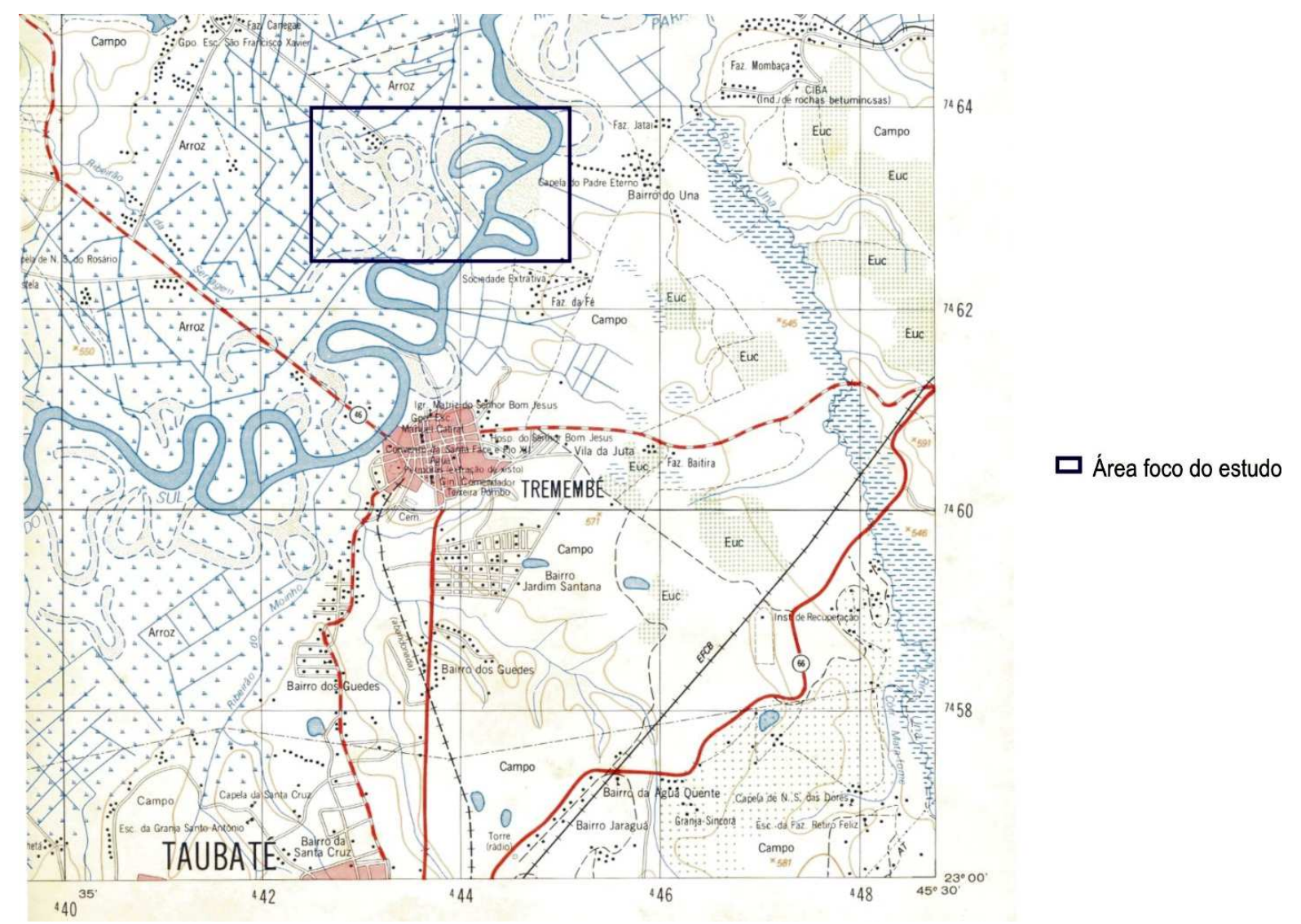

Figura 1. Localização da área do estudo no município de Tremembé.

Foram construídos, em quatro pontos distintos da Mineração Paraíso, conjuntos de piezômetros (de 2" e 4" de diâmetro) para fins de monitoramento dos níveis d'água do aquífero freático, realização de bombeamento e monitoramento da qualidade da água. Durante a construção destes piezômetros e dos ensaios SPT foram coletadas amostras de metro em metro e enviadas para laboratório para caracterização granulométrica dos solos e sedimentos. Também, em alguns locais amostrados para caracterização geológica/geotécnica dos solos, foram coletadas amostras para ensaios granulométricos.

As amostras colhidas foram acondicionadas em sacos plásticos herméticos e levadas ao Laboratório de Sedimentologia do Instituto Geológico, onde as análises granulométricas foram executadas, utilizando-se o método do peneiramento para separação das frações areia e pedregulho, e o método da sedimentação ou do densímetro para a quantificação das frações silte-argilosas.

De acordo com a Norma Brasileira 6484/1980, que prescreve o método de execução de sondagens a percussão, o ensaio foi iniciado com o amostrador padrão, conectado às hastes de perfuração, sendo que este desceu até ser apoiado no fundo. A cabeça de bater foi colocada no topo da haste e o martelo foi apoiado sobre a cabeça de bater. Marcou-se na haste de perfuração, com fita adesiva, um segmento de $0,45 \mathrm{~m}$ dividido em três trechos iguais de 0,15 $\mathrm{m}$. Para que houvesse a cravação do martelo de $63,5 \mathrm{kgf}$, o mesmo foi erguido até a altura de $0,75 \mathrm{~m}$, marcado nas hastes guias, e então foi deixado em queda totalmente livre. Foram anotados, separadamente, o número de golpes necessários à cravação de cada $0,15 \mathrm{~m}$ do amostrador. Estas e outras informações observadas encontram-se no Boletim da Sondagem SPT, Figura 3. 


\section{Resultados}

\subsection{Aplicação dos Índices Físicos}

Na Tabela 1 são mostrados os parâmetros físicos do solo obtidos em laboratório e os Índices Físicos determinados por meio de fórmulas de correlação entre eles. Para os Índices Físicos obtidos nas amostras retiradas do solo da área da várzea do rio Paraíba do Sul, em quatro profundidades, variáveis entre $0,5 \mathrm{~m}$ e $2 \mathrm{~m}$. As coordenadas UTM do local amostrado são as seguintes: $443,708 \mathrm{~km}$ E e $7463,413 \mathrm{~km} \mathrm{~N}$. Obteve-se a média de $66 \%$ de porosidade, $40 \%$ de saturação e $60 \%$ de aeração.

Estes valores médios encontrados, Porosidade $(n)$ igual a $66 \%$ e Grau de Saturação $\left(S_{\mathrm{r}}\right)$ igual a $40 \%$, são utilizados para determinar-se a Capacidade de Armazenamento $\left(C_{\mathrm{A}}\right)$ e o Armazenamento Unitário $\left(A_{\mathrm{U}}\right)$.

Como, $C_{\mathrm{A}}=n-n \times S_{\mathrm{r}}$, então

$C_{\mathrm{A}}=0,66-0,66 \times 0,40=0,4$.

$A_{\mathrm{U}}=0,4 \mathrm{~m}^{3}$.

Sendo, $A_{\mathrm{U}}=1 \mathrm{~m}^{3} \times C_{\mathrm{A}}$, temos

Ou seja, para cada 0,4 m de lâmina d'água infiltrada obter-se-á $1 \mathrm{~m}$ de subida do nível d'água do aquífero freático. Mas, para cada acréscimo na subida do nível d'água ou aumento do potencial hidráulico haverá, como mecanismo compensatório, um aumento equivalente na descarga da água do aquífero freático nas fontes.

Tabela 1. Índices Físicos de amostras de solo da várzea do rio Paraíba do Sul, em Tremembé

\begin{tabular}{|c|c|c|c|c|}
\hline & & Teor de umidade & Massa específica natural & Massa específica dos sólidos \\
\hline $\mathbf{n}^{\mathbf{0}}$ amostra & Profundidade $(\mathbf{m})$ & $\mathbf{w}$ & $\boldsymbol{\gamma}\left(\mathbf{g} / \mathbf{c m}^{\mathbf{3}}\right)$ & $\boldsymbol{\gamma}_{\mathbf{s}}\left(\mathbf{g} / \mathbf{c m}^{\mathbf{3}}\right)$ \\
\hline 1 & 0,5 & 0,33 & 1,16 & 2,67 \\
\hline 2 & 1,0 & 0,29 & 1,22 & 2,78 \\
\hline 3 & 1,5 & 0,26 & 1,21 & 2,69 \\
\hline 4 & 2,0 & 0,26 & 1,20 & 2,73 \\
\hline média & & 0,29 & 1,20 & 0,57 \\
\hline & & & & Grau de Aeração $(A)$ \\
\hline $\mathbf{n}^{\mathbf{0}}$ amostra & Índice de vazios & Porosidade $(n)$ & Grau de Saturação $\left(S_{\mathrm{r}}\right)$ & 0,58 \\
\hline 1 & 2,06 & 0,67 & 0,43 & 0,61 \\
\hline 2 & 1,94 & 0,66 & 0,42 & 0,62 \\
\hline 3 & 1,80 & 0,64 & 0,39 & 0,60 \\
\hline 4 & 1,90 & 0,65 & 0,38 & \\
\hline média & 1,92 & 0,66 & 0,40 & \\
\hline
\end{tabular}

\subsection{Classificação granulométrica dos depósitos arenosos}

Na Figura 2 é mostrado um diagrama triangular de classificação granulométrica de amostras obtidas durante o ensaio de penetração, no local do conjunto de piezômetros $n^{0} 4$ (poço de 4"). Foram ensaiadas as amostras coletadas em diversas profundidades, variáveis entre 3 e $7 \mathrm{~m}$. Nos outros 3 conjuntos de piezômetros de 2 e 4 " também foram determinados e classificados os depósitos predominantemente arenosos. 


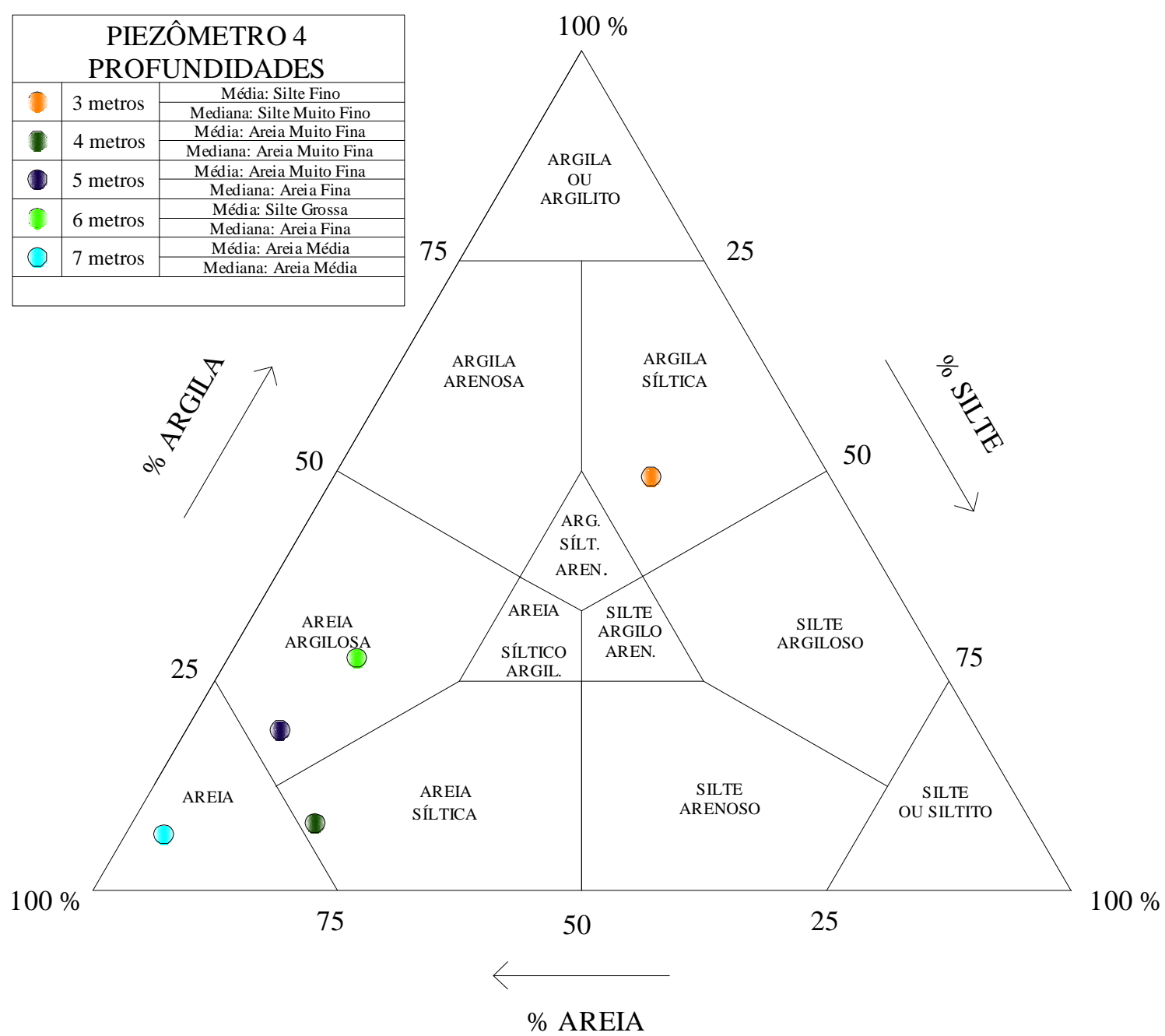

Figura 2. Distribuição textural das amostras obtidas no piezômetro 4 em diferentes profundidades.

\subsection{Sondagem SPT}

Foram realizadas sondagens à percussão em todos os locais escolhidos para a instalação dos piezômetros. A Figura 3 apresenta os resultados obtidos no local 4 do conjunto de piezômetros.

\section{Projeções Futuras}

Para a realização do projeto "Interferência entre cavas de extração de areia e o aquífero freático na margem do rio Paraíba do Sul, Município de Tremembé", foram adquiridos os seguintes materiais para instalação e medidas de campo: oito medidores automáticos de nível d'água, um medidor de qualidade de água multiparâmetros, um analisador de demanda bioquímica de oxigênio e uma estação hidroclimática. Com estes equipamentos serão levantadas as condições hidráulicas, climáticas e hidroquímicas existentes entre as cavas de extração de areia e as alterações nas condições de armazenamento e qualidade da água do aquífero freático, na área da mineração Paraíso, na várzea do rio Paraíba do Sul e, também, avaliar a interferência provocada no aquífero freático pelas inundações realizadas para o plantio de arroz. Serão tomadas como modelo cavas abandonadas e em operação, assim como 
áreas de proteção permanente com mata natural e áreas de irrigação de arroz, situadas no município de Tremembé.

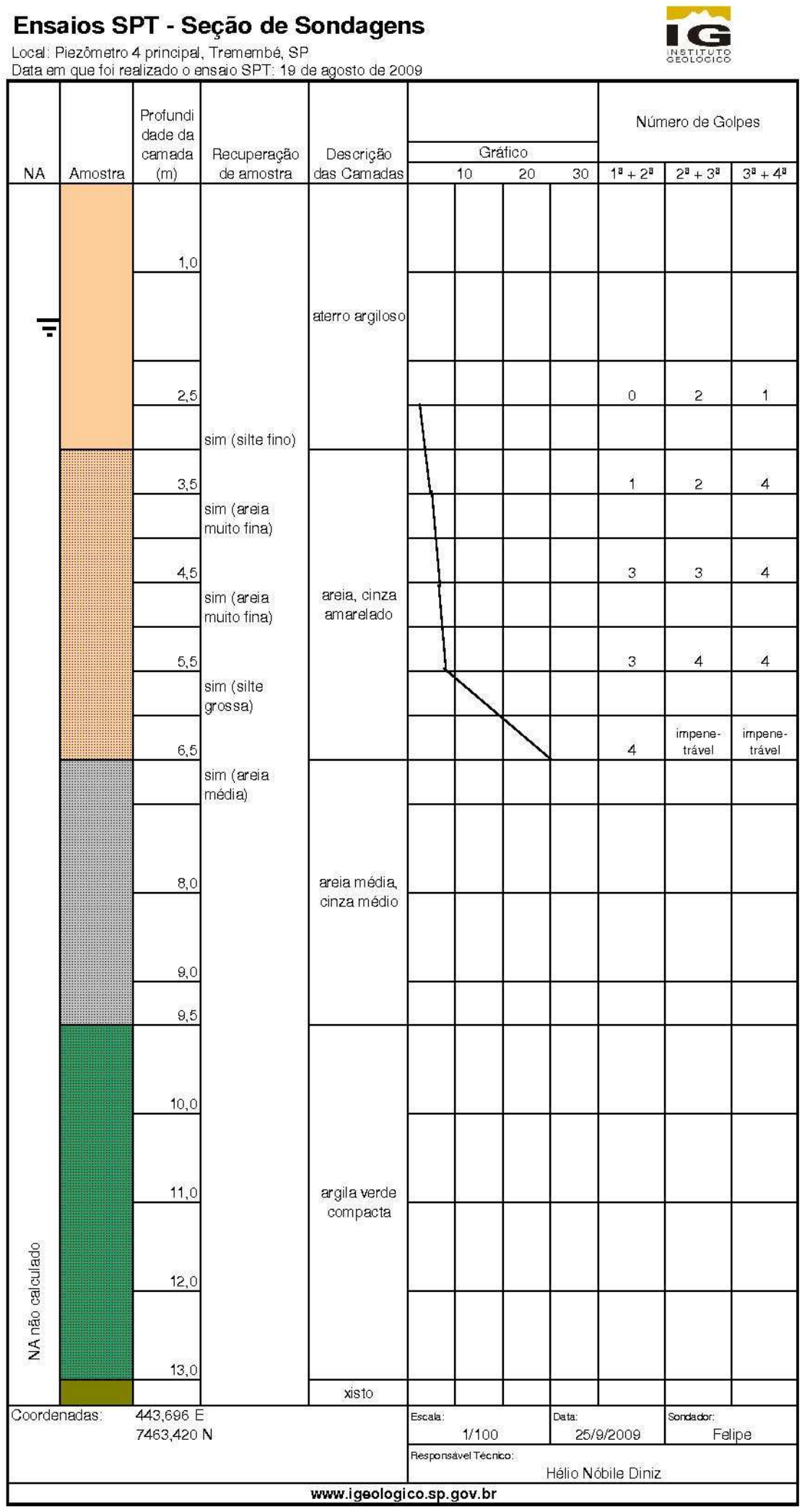

Figura 3. Ensaios SPT no local do piezômetro 4 


\section{Referências}

ABNT - Associação Brasileira de Normas Técnicas. NBR 6484-1980. Execução de sondagens de simples reconhecimento dos solos - Método de ensaio.

ANEPAC. Vale do Paraíba: maior região produtora de areia do país. Revista Areia \& Brita, São Paulo, n. 10, p. 5-19, abr. - jun. 2000.

ARANHA, P.R.A. e SOBREIRA, F.G. Utilização do Geo-radar na identificação de feições associadas ao escorregamento ocorrido em Realeza, Manhuaçu -MG - Revista Revista de Geologia, Vol. 19, n 1, 35-47, 2006 de Geologia, Vol. 19, nº 1, 35-47, 2006 www.revistadegeologia.ufc.br

BUENO, B.S. e VILAR, O.M. 1984. Mecânica dos Solos. Escola de Engenharia de São Carlos/Departamento de Geotecnia, Publicação 004/85, São Carlos, 131 p.

NOGUEIRA, J.B. 1995. Mecânica dos solos - Ensaios de laboratório. EESC-USP, São Carlos, 248p.

REIS, B. J. 2005. Avaliação da Expansão da Atividade de Extração de Areia na Planície Aluvial da Bacia Hidrográfica do Rio Paraíba do Sul no trecho entre Jacareí e Pindamonhangaba no período de 1993 a 2003. Dissertação de Mestrado em Ciências Ambientais, Universidade de Taubaté, Taubaté, 112 p.

SANTORO, J. 1991. Fenômenos erosivos acelerados na região de São Pedro - S.P. Estudo da fenomenologia com ênfase geotécnica. Rio Claro S.P. Dissertação de mestrado. IGCE - UNESP - Campus de Rio Claro S.P. 140p. il.

STANCATI, G; NOGUEIRA, J.B.; VILAR, O.M. 1981. Ensaios de laboratório em mecânica dos solos. EESC USO, Publicação 004/87, São Carlos, 208p. il. 